\title{
Prediction of density and volume variation of hematite ore particles during in-flight melting and reduction
}

\author{
Zhi-yuan Chen $^{1}$ (1) $\cdot$ Ying-xia $\mathrm{Qu}^{2} \cdot$ Christiaan Zeilstra $^{3} \cdot$ Jan Van Der Stel ${ }^{3} \cdot$ Jilt Sietsma $^{1} \cdot$ Yong-xiang Yang $^{1}$
}

Received: 30 July 2018/Revised: 10 January 2019/Accepted: 16 January 2019/Published online: 13 April 2019

(C) The Author(s) 2019

\begin{abstract}
HIsarna is a promising ironmaking technology to reduce $\mathrm{CO}_{2}$ emission. Information of phase transformation is essential for reaction analysis of the cyclone reactor of the HIsarna process. In addition, data of density and volume of the ore particles are necessary for estimation of the residence time of the particles in the cyclone reactor. Phase transformation of iron ore particles was experimentally studied in a drop-tube furnace under simulated cyclone conditions and compared with thermodynamic calculation. During the pre-reduction process inside the reactor, the mineralogy of iron ore particles transforms sequentially from hematite to sub-oxides. The density changes of the particles during the melting and reduction can be predicted based on the phase composition and temperature. Therefore, density models in the studies were evaluated with reported experimental data of slag. As a result, a more reliable density model was developed to calculate the density of the formed slag containing mainly $\mathrm{FeO}-\mathrm{Fe}_{2} \mathrm{O}_{3}$. The density and volume of the partially reduced ore particles or melt droplets were estimated based on this model. The results show that the density of the ore particles decreases by $15.1 \%$ at most along the progressive reduction process. Furthermore, the model results also indicate that heating, melting and reduction of the ore could lead to $6.63-9.37 \%$ swelling of the particles, which is mostly contributed by thermal expansion. It would result in corresponding variation in velocity of the ore particles or melt droplets during the flight inside the reactor.
\end{abstract}

Keywords Ironmaking process $\cdot$ HIsarna $\cdot$ Smelting reduction $\cdot$ Ore density change $\cdot$ Phase transformation · Hematite ore particle

\section{Introduction}

HIsarna is an emerging and promising alternative ironmaking process. It can directly convert iron ore particles into liquid iron with at least $20 \%$ smaller carbon footprint as the present mode. A reduction in $\mathrm{CO}_{2}$ emissions by $80 \%$ could be achieved combining with capturing and storing of waste gases. A smelt cyclone is used to melt and pre-reduce fine and non-agglomerated iron ore particles in

$\triangle$ Zhi-yuan Chen

Z.Chen-5@tudelft.nl; aha_c@126.com

1 Department of Materials Science and Engineering, Delft University of Technology, Delft 2628 CD, The Netherlands

2 School of Metallurgical Engineering, Northeastern University, Shenyang 110819, Liaoning, China

3 Tata Steel Europe, Ijmuiden 1970 CA, The Netherlands
HIsarna reactor. Fine ore and flux are injected into the cyclone reactor together with oxygen. The injected ore is intensely mixed with rising hot reducing gases, undergoing partial reduction and melting. The melt hits the watercooled sidewalls of the cyclone section, flows down along with the wall and drips into the liquid bath in the smelting reduction vessel (SRV) where the final reduction takes place $[1,2]$. The ore in the cyclone section is pre-reduced to about $20 \%$ through thermal decomposition and reduction by the SRV gas $\left(\mathrm{CO}\right.$ and $\left.\mathrm{H}_{2}\right)$. The temperature of the melts in the SRV is approximately $1723 \mathrm{~K}$ [3]. Variation in the ore particles state is difficult to visualize inside the cyclone and analyse through probing and sampling. Therefore, theoretical estimation is extremely important under these conditions.

One of the widely studied properties of the ore during reduction is the shrinkage, sometimes swelling, of the ferrous raw materials, which affect the internal heat transport and the diffusion of gas [4]. In addition, changes 
in density and volume of the particles are the key parameters to estimate the residence time of the particles in the cyclone [5-7]. Most research contributions are in the field of the pellet reduction and less in the area of single ore particle. Seaton et al. [8] demonstrated that the swelling at high temperatures (1373 and $1473 \mathrm{~K}$ ) relates to the transformation of wustite to iron in the pellet, and the shrinkage was due to the sintering of iron filaments. Sharma et al. [9] observed that growth of iron whiskers resulted in swelling of pellet at the low temperature $(1273 \mathrm{~K})$. Rau et al. [10] indicated that the phase transformation causes the shrinkage of single crystal iron oxides and then leads to the fissure of material. The kinetic models published by Hayashi and Iguchi [7] and Tsukihashi et al. [11] also consider the shrinkage of liquid iron oxides fines as the result of density change due to phase conversion. Halder and Fruehan [12] suggested that the shrinkage is caused by the loss of oxygen from the oxides, sintering of iron oxide and formation of a molten slag phase. Also, according to the textbook of German [13], Halder and Fruehan suggested that good slag wettability, high diffusion rates in liquids and more slag formation benefit shrinkage. Donskoi and McElwain [14] developed a mathematical model to predict phenomena, including shrinkage of char composite pellet. Reaction temperature and porosity of pellet were considered to be the two principal parameters to regulate the shrinkage. They suggested that the local volume change of pellet is due to the sum of shrinkage and swelling. The shrinkage is the function of porosity and temperature, and the swelling is affected by the volume fraction of phases and temperature. Another attempt of modelling on shrinkage has been carried out by Fortini and Fruehan [15], where an empirical equation was given, which shows the positive effect of temperature on shrinkage. They also proposed that the shrinkage of the pellet is closely related to the fraction of pore in it.

Unlike the abundant pellet studies, there are rare studies of particles, while the latter is important to the study of HIsarna process. A single particle is much less porous than a pellet. Hereby, we proposed that the density variation of particles is principally influenced by the phase transformation in the reaction. Phase transformation is mainly due to chemical reactions and high-temperature melting behaviour of the ore. Therefore, phase transformation is essential information for the analysis. Based on the phase analysis, a modified model was developed specifically for estimation of the density and specific volume of the iron ore particles during the partial reduction process at high temperature. At last, the effects of the density and specific volume of particle on the falling rate of it in a drop-tube furnace were evaluated.

\section{Experimental}

To investigate the behaviour of individual particles in the smelt cyclone part of HIsarna reactor, the study was carried out with a high-temperature drop-tube furnace (HDTF, Fig. 1), which is a laminar flow reactor. The length of the hot zone for reaction is $390 \mathrm{~mm}$, with the inner diameter of the alumina tube of $60 \mathrm{~mm}$. The direction of the gas flow is also shown in Fig. 1. The total gas flow rate is $2 \mathrm{~L} / \mathrm{min}$. The reacting gas has been heated up to $773 \mathrm{~K}$ before injection into the furnace. With distribution of the gas to the carrying gas and reacting gas pipes, the falling velocity of the particles can be controlled. Usually, the Reynolds number for the particle is lower than 1 , which means that the falling particle is in a Stokes flow. The whole system, including the sample collector, is in reducing atmospheres. The experimental details were described in Refs. [3, 6]. Hematite ore particles with an average size of $67 \mu \mathrm{m}$ reacted with 45 vol.\% $\mathrm{CO}-55$ vol.\% $\mathrm{CO}_{2}$ gas ( $\mathrm{P} 1$ gas, more reducing) and 5 vol.\% $\mathrm{CO}-95$ vol. $\% \mathrm{CO}_{2}$ gas (P2 gas, less reducing) in the HDTF from 1710 to $1760 \mathrm{~K}$, respectively. Table 1 shows the chemical composition of the ore particles, where the rest minerals of less than 1 mass\% will not be considered in the density estimation. The composition is measured by $\mathrm{X}$-ray fluorescence (Panalytical Axios Max WD-XRF spectrometer). The CO$\mathrm{CO}_{2}$ gas mixture was divided into two paths: carrier gas flow to transport hematite ore particles to the isothermal zone of HDTF and reacting gas flow which was preheated

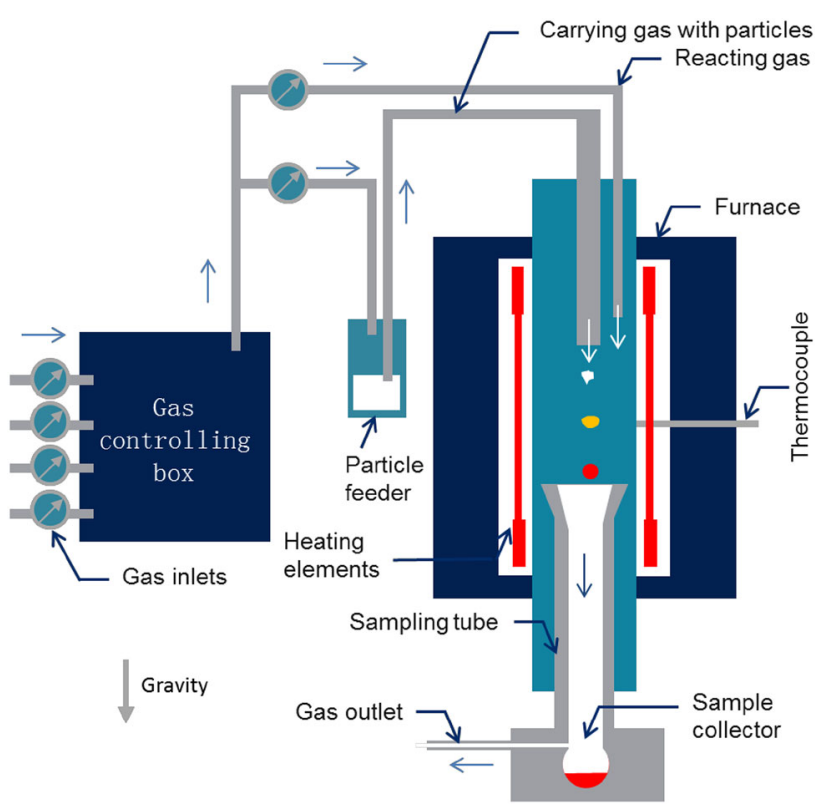

Fig. 1 Illustration of high-temperature drop-tube furnace and gas flow direction 
Table 1 Chemical composition of hematite ore particles (mass\%)

\begin{tabular}{lccccccrr}
\hline Component & $\mathrm{Fe}_{2} \mathrm{O}_{3}$ & $\mathrm{SiO}_{2}$ & $\mathrm{Al}_{2} \mathrm{O}_{3}$ & $\mathrm{CaO}$ & $\mathrm{MgO}$ & $\mathrm{MnO}^{2}$ & $\mathrm{TiO}_{2}$ & $\mathrm{Others}$ \\
\hline Content & 72.354 & 14.030 & 4.985 & 2.974 & 2.524 & 1.429 & 0.721 & 0.983 \\
Error & 0.100 & 0.100 & 0.070 & 0.050 & 0.050 & 0.040 & 0.030 \\
\hline
\end{tabular}

for the reaction with particles. The reaction time was controlled by the flow rate of the carrying gas and the reacting gas flow. After pre-reduction, the collected particles were analysed by X-ray diffraction (XRD, Bruker D8 Advance diffractometer Bragg-Brentano geometry and Lynxeye position-sensitive detector). The step size in the $\mathrm{XRD}$ measurement is $0.030^{\circ}(2 \theta)$, with counting time per step of $2 \mathrm{~s}$.

\section{Results and discussion}

\subsection{Phase transformation}

Figure 2 shows the typical XRD patterns of the ore particles after reaction for $\sim 230 \mathrm{~ms}$ at $1735 \mathrm{~K}$ in different atmospheres. It indicates that the principal phases in the reduced samples are magnetite and wustite. Wustite content in the sample reduced in P2 gas is far less than that in the sample reduced in $\mathrm{P} 1$ gas. In most samples (the patterns of which were not presented here), amorphous $\mathrm{SiO}_{2}$ is the principal gangue phase. Besides, $\mathrm{CaO}$ crystal was detected out in some samples, which is no more than 2 mass $\%$. Regardless of non-ferrous minerals (the gangue), the quantitative analysis results of XRD patterns are shown in Fig. 3. The precision of the data is within 1.0 mass $\%$. The accuracy of the quantitative analysis results was checked

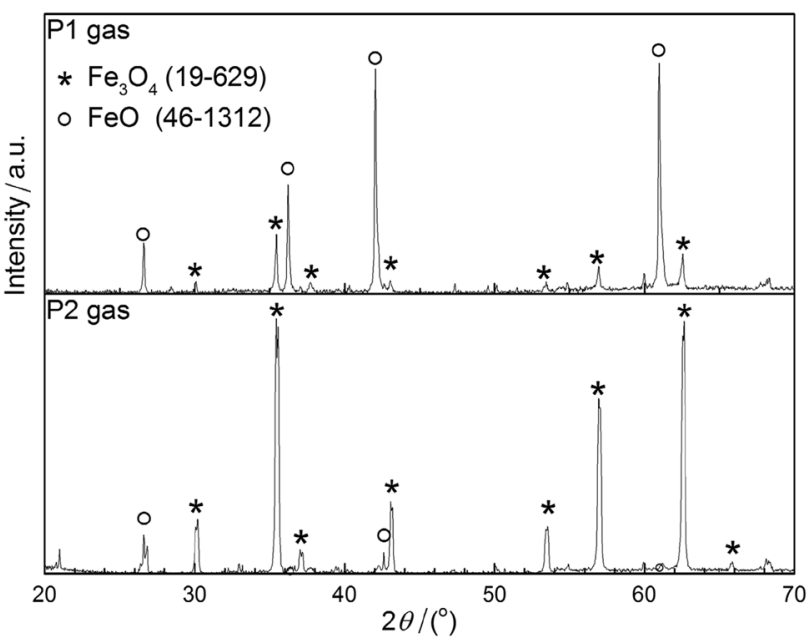

Fig. 2 XRD patterns of ore particles after reaction for around $230 \mathrm{~ms}$ at $1735 \mathrm{~K}$ in $\mathrm{P} 1$ and $\mathrm{P} 2$ gases by comparing with the chemical analysis, showing that the highest relative error is $16 \%$. It is found that the relative error is less with higher oxygen content in the particles. For instance, the relative error of the results in $\mathrm{P} 2(5 \% \mathrm{CO}-$ $95 \% \mathrm{CO}_{2}$ ) gas is around $5.0 \%$. It indicates that the initial reaction rate is higher. Hematite has been completely reduced into sub-oxides within $200 \mathrm{~ms}$ either in P1 or P2 gases. After reaction for $200 \mathrm{~ms}$, the content of magnetite decreases and the content of wustite increases. With the increase in temperature and $\mathrm{CO}$ concentration in reducing gas, the content of wustite increases. Theoretically, the reduction from $\mathrm{Fe}_{2} \mathrm{O}_{3}$ to $\mathrm{Fe}_{3} \mathrm{O}_{4}$ and $\mathrm{FeO}$ results in $3.34 \%$ and $10.00 \%$ mass loss, respectively. The mass loss creates structure changes, leading to density and volume variations.

As Fig. 4 shows, morphology of particles changes with variation of phase composition. Because the reaction temperature range is between 1710 and $1760 \mathrm{~K}, \mathrm{FeO}$ (melting point $1650 \mathrm{~K}$ ) is in a liquid phase, and $\mathrm{Fe}_{3} \mathrm{O}_{4}$ (melting point $1870 \mathrm{~K}$ ) is in a solid phase in the experiments. It was observed that the reduced particles in P1 gas are spherical particles, and those in P2 gas are deformed particles. It indicates that the principal phase in the former particles is molten slag, and the latter particles are mixtures of solid and liquid in the reaction. Moreover, melting behaviour of wustite-containing slag can change the particle density and volume. It is known from previous studies [5-7] that the particle size and density affect the drag force on the particle in falling down through the reactor. As a result, the residence time of particle can be varied during the reaction.

\subsection{Density model}

The true density of iron oxide ore could be calculated out based on the phase composition values without consideration of porosity. The density of solid and slag $\rho$ is satisfied regarding respective constitutive compounds as [16-18]:

$\rho=\sum_{i} x_{i} \rho_{i}$

where $x_{i}$ and $\rho_{i}$ represent the mole fraction of the component $i$ and the density of pure component $i$ in liquid or solid state (note here we extended it to a solid state of dense materials), respectively. Moreover, the relationship 

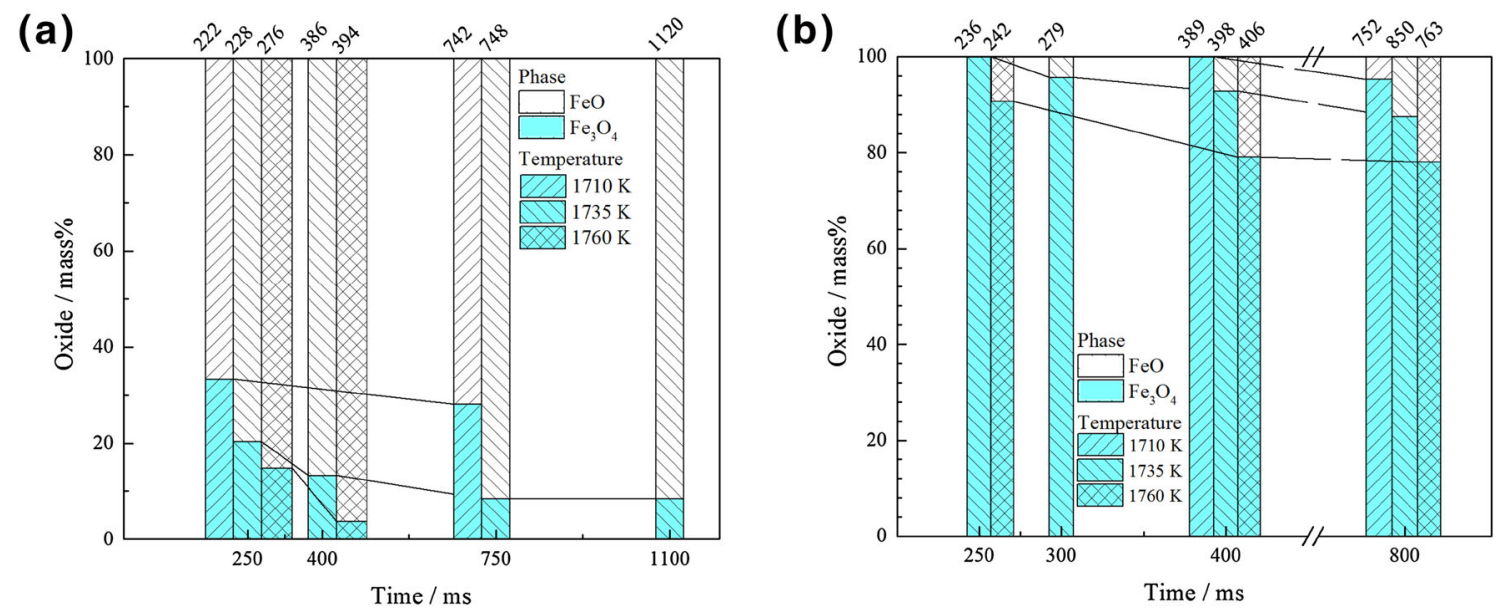

Fig. 3 Phase composition of samples reacted in P1 gas (a) and P2 gas (b). Numbers above are real reaction time for corresponding bars
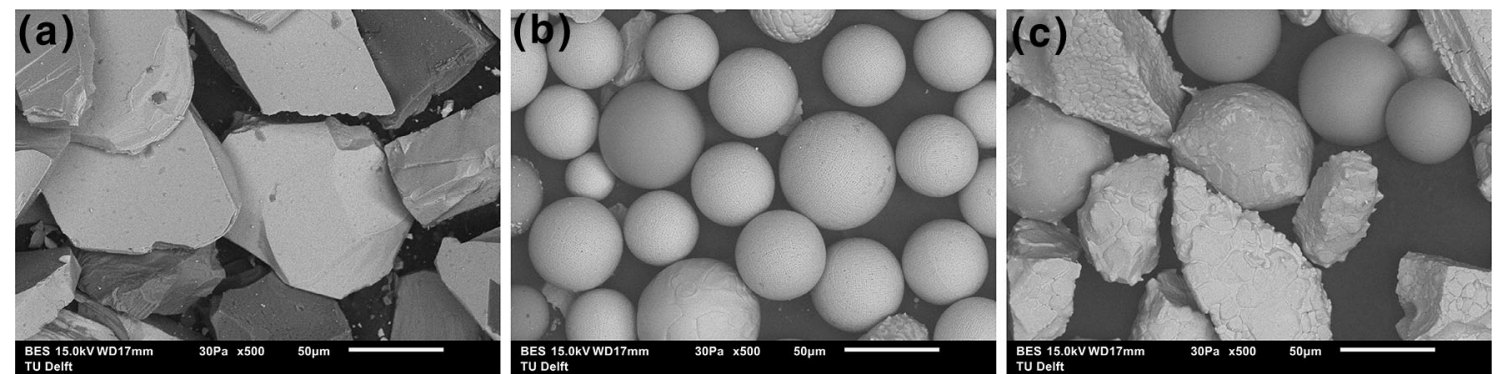

Fig. 4 Ore particles before reaction (a) and reacted after $750 \mathrm{~ms}$ in P1 gas (b) and $850 \mathrm{~ms}$ in P2 gas (c) at $1735 \mathrm{~K}$

between the molar volume of component, $V_{i}$, and $\rho_{i}$ is as follows:

$\rho_{i}=M_{i} / V_{i}$

where $M_{i}$ is the molar mass of the component $i$.

The reason for using this simple equation to calculate the density of slag is that although model of solution could be employed to predict the physical parameters, previous studies [19-21] implied that the accuracy of arithmetic addition of all constitutive compounds is sufficient. For instance, experimental results of Shiraishi et al. [22] on the density of $\mathrm{FeO}-\mathrm{SiO}_{2}$ system show a linear relationship of slag density to mole fraction of $\mathrm{SiO}_{2}$ at $1673 \mathrm{~K}$. Also, the work of Vadász et al. [23] on $\mathrm{CaO}-\mathrm{FeO}-\mathrm{Fe}_{2} \mathrm{O}_{3}-\mathrm{MgO}$, $\mathrm{CaO}-\mathrm{FeO}-\mathrm{Fe}_{2} \mathrm{O}_{3}-\mathrm{ZnO}$ and $\mathrm{CaO}-\mathrm{Fe}_{2} \mathrm{O}_{3}-\mathrm{Cu}_{2} \mathrm{O}$ systems shows linear relationships of the molar volume of the melts with the content of the respective substances. Therefore, the density of the present slag system is estimated based on Eq. (1).

Firstly, the density of the respective solid substances, $\rho_{i}$, can be evaluated based on the reference data. Table 2 lists the densities of compounds, in which the densities of most compounds in solid phase are same according to FactSage 7.0. And the temperature ranges of present experiments are included in that of the reference data. The values of expansivities are also provided in FactSage 7.0 except for $\mathrm{MnO}$ as follows:

$\gamma=a T+b \times T+c / T+d / T^{2}$

where $T$ is the temperature; $\gamma$ is the volumetric thermal expansion coefficient; and $a, b, c$ and $d$ are coefficients, and their values are shown in Table 3. The expansivity of $\mathrm{MnO}$ was assumed to be zero in this work.

Table 2 Densities of compounds at room temperature in FactSage 7.0

\begin{tabular}{|c|c|c|c|c|c|c|c|c|c|c|}
\hline Component & Lime & $\mathrm{MnO}$ & Corundum & Magnetite & Hematite & Rutile & $\alpha$-quartz & $\beta$-quartz & Wustite & Periclase \\
\hline Density/( $\left.\mathrm{g} \mathrm{cm}^{-3}\right)$ & 3.346 & 5.45 & 3.987 & 5.201 & 5.277 & 4.245 & 2.649 & 2.63 & 5.865 & 3.583 \\
\hline $\begin{array}{l}\text { Molar volume/ } \\
\left(\mathrm{cm}^{3} \mathrm{~mol}^{-1}\right)\end{array}$ & 16.76 & 13.016 & 25.693 & 44.517 & 30.262 & 18.814 & 22.680 & 25.73 & 12.250 & 16.298 \\
\hline
\end{tabular}


Table 3 Parameters in thermal expansion coefficient equation of compounds in FactSage 7.0

\begin{tabular}{|c|c|c|c|c|c|c|c|c|}
\hline Parameter & Rutile & Lime & $\alpha$-quartz & $\beta$-quartz & Corundum & Periclase & Hematite & Magnetite \\
\hline$a$ & $2.02 \times 10^{-5}$ & $3.36 \times 10^{-5}$ & $2.75 \times 10^{-5}$ & $2.06 \times 10^{-5}$ & $4.20 \times 10^{-5}$ & $3.64 \times 10^{-5}$ & $2.45 \times 10^{-5}$ & $2.61 \times 10^{-5}$ \\
\hline$b$ & $1.48 \times 10^{-8}$ & $5.44 \times 10^{-9}$ & $2.99 \times 10^{-8}$ & $3.47 \times 10^{-8}$ & $-8.00 \times 10^{-10}$ & $8.35 \times 10^{-9}$ & $1.67 \times 10^{-8}$ & $3.26 \times 10^{-8}$ \\
\hline$c$ & $-2.73 \times 10^{-3}$ & $-1.20 \times 10^{-5}$ & $5.57 \times 10^{-6}$ & $1.31 \times 10^{-4}$ & $-1.14 \times 10^{-2}$ & $8.50 \times 10^{-4}$ & 0 & 0 \\
\hline$d$ & $5.17 \times 10^{-2}$ & $-4.34 \times 10^{-1}$ & $9.12 \times 10^{-2}$ & -1.64 & 1.06 & $-9.50 \times 10^{-1}$ & $2.00 \times 10^{-3}$ & $4.00 \times 10^{-3}$ \\
\hline
\end{tabular}

According to the phase composition analysis, one could notice that the main change in density of dense materials is due to the reduction of $\mathrm{Fe}_{2} \mathrm{O}_{3}$. The volume shrinkages from $\mathrm{Fe}_{2} \mathrm{O}_{3}$ to $\mathrm{Fe}_{3} \mathrm{O}_{4}$ and solid $\mathrm{FeO}$ are $1.93 \%$ and $19.00 \%$, respectively. It indicates that a significant shrinkage of the ore particle happens with the formation of $\mathrm{FeO}$. Correspondingly, the density changes in the reduction from $\mathrm{Fe}_{2} \mathrm{O}_{3}$ to $\mathrm{Fe}_{3} \mathrm{O}_{4}$ and solid $\mathrm{FeO}$ are $1.43 \%$ decrease and $11.10 \%$ increase, respectively. In other words, reduction from hematite to magnetite results in swelling of the solid, while the reduction from hematite to solid wustite results in shrinkage.

Meanwhile, the density of slag components is surveyed. Ji et al. [16] reported the optimized density of $\mathrm{CaO}, \mathrm{SiO}_{2}$ and $\mathrm{Fe}_{n} \mathrm{O}$ in liquid phases to be $3.3,2.3$ and $4.7 \mathrm{~g} / \mathrm{cm}^{3}$. It could be noticed that the values for liquid oxides are different from those in the solid state. Shiraishi et al. [22] reported a volume change of wustite on fusion to be $17.5 \%$, which corresponds to the molar volume change from 13.43 to $15.78 \mathrm{~cm}^{3} / \mathrm{mol}$. Furthermore, they suggested that volume change on fusion is about $20-30 \%$ in the case of ionic crystals. Usually, there is a linear relationship between density/molar volume of slag composition and temperature $[17,24]$.

Hara et al. [25] reported a model to predict the densities of $\mathrm{FeO}-\mathrm{Fe}_{2} \mathrm{O}_{3}-\mathrm{CaO}$ at 1673,1773 and $1873 \mathrm{~K}$ in an accuracy of $0.5 \%$, while they found differences between their predicted data and the data reported by Lee and Gaskell [26] as well as Mori and Suzuki [27] for FeO$\mathrm{Fe}_{2} \mathrm{O}_{3}$ in unclear reasons. We conjecture that the critical technology of controlling the valence state of iron ions could be a principal reason of the disagreement within the reported data. As a proof of this opinion, Shiraishi et al. [22] detected 9.99 mass $\% \mathrm{Fe}_{2} \mathrm{O}_{3}$ in the measurement of pure $\mathrm{FeO}$ melts.

Mills et al. [28, 29] reported the relationship of the partial molar volume of molten slag components and temperature in the form of:

$V_{\mathrm{SiO}_{2}}=\left(19.55+7.966 x_{\mathrm{SiO}_{2}}\right)\left[1+10^{4}(T-1773)\right] \quad \mathrm{cm}^{3} / \mathrm{mol}$

$$
\begin{aligned}
& V_{\mathrm{Al}_{2} \mathrm{O}_{3}}=\left(28.3+32 x_{\mathrm{Al}_{2} \mathrm{O}_{3}}-31.45 x_{\mathrm{Al}_{2} \mathrm{O}_{3}}^{2}\right)\left[1+10^{-4}(T-1773)\right] \\
& \mathrm{cm}^{3} / \mathrm{mol} \\
& V_{\mathrm{CaO}}=20.7\left[1+10^{-4}(T-1773)\right] \quad \mathrm{cm}^{3} / \mathrm{mol} \\
& V_{\mathrm{FeO}}=15.8\left[1+10^{-4}(T-1773)\right] \quad \mathrm{cm}^{3} / \mathrm{mol} \\
& V_{\mathrm{MgO}}=16.1\left[1+10^{-4}(T-1773)\right] \quad \mathrm{cm}^{3} / \mathrm{mol} \\
& V_{\mathrm{MnO}}=15.6\left[1+10^{-4}(T-1773)\right] \quad \mathrm{cm}^{3} / \mathrm{mol} \\
& V_{\mathrm{Fe}_{2} \mathrm{O}_{3}}=38.4\left[1+10^{-4}(T-1773)\right] \quad \mathrm{cm}^{3} / \mathrm{mol} \\
& V_{\mathrm{TiO}_{2}}=24\left[1+10^{-4}(T-1773)\right] \quad \mathrm{cm}^{3} / \mathrm{mol}
\end{aligned}
$$

The estimated values of the Mills-Keene model are shown in Fig. 5a. In that model, molar volumes of $\mathrm{SiO}_{2}$ and $\mathrm{Al}_{2} \mathrm{O}_{3}$ vary with their molar fractions in slag. The molar fractions of $\mathrm{SiO}_{2}$ and $\mathrm{Al}_{2} \mathrm{O}_{3}$ were assumed to vary within $0.039-0.250$ and $0.007-0.026$ in the estimation, respectively. Because Mills and Keene [28] assumed that the thermal expansion of slag is in a mean value of $0.01 \% \mathrm{~K}^{-1}$, the lines in Fig. 5a are parallel to each other.

In order to verify this model, we collected the reported molar volumes of principal substances in iron-oxides-rich slags as listed in Table 4. Figure $5 \mathrm{~b}$ shows the data in Table 4 and the linear fitting results. It is different from the modelling data in Fig. 5a. Although the empirical model of Mills and Keene has been successfully used to estimate the densities of $\mathrm{CaO}-\mathrm{SiO}_{2}-\mathrm{FeO}$ melts at $1823 \mathrm{~K}$ [30], Fig. 5 implies that a modification of the model is required for iron-oxides-rich slag.

A strategy was adopted for determining the molar volume of the minor compounds in the iron-oxides-rich slag; that is, $\mathrm{MgO}, \mathrm{MnO}$ and $\mathrm{Al}_{2} \mathrm{O}_{3}$ are calculated via the MillsKeene model, and the other four compounds are predicted using the linear fitting results in Fig. 5a as a modification of their model. The details of the equations as fitting results of Fig. 5a are as follows:

$$
\begin{aligned}
& V_{\mathrm{SiO}_{2}}=38.96-7.64 \times 10^{-3} T \quad \mathrm{~cm}^{3} / \mathrm{mol} \\
& V_{\mathrm{CaO}}=3.91+8.56 \times 10^{-3} T \quad \mathrm{~cm}^{3} / \mathrm{mol}
\end{aligned}
$$


(a)

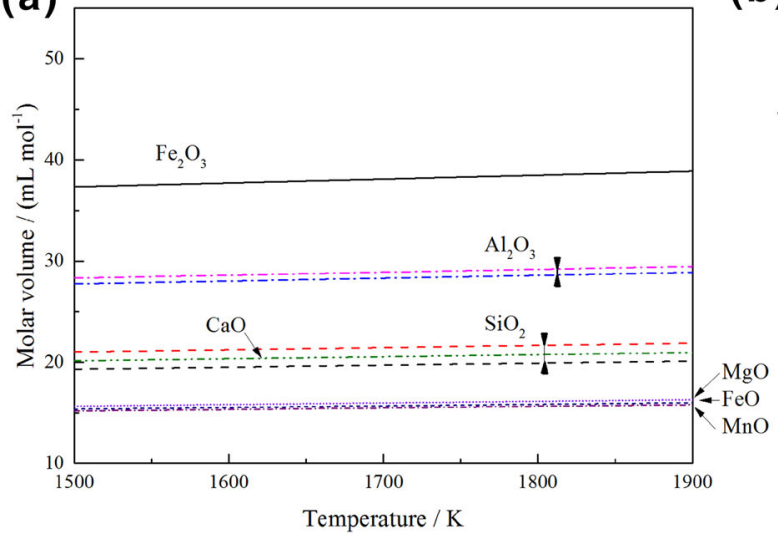

(b)

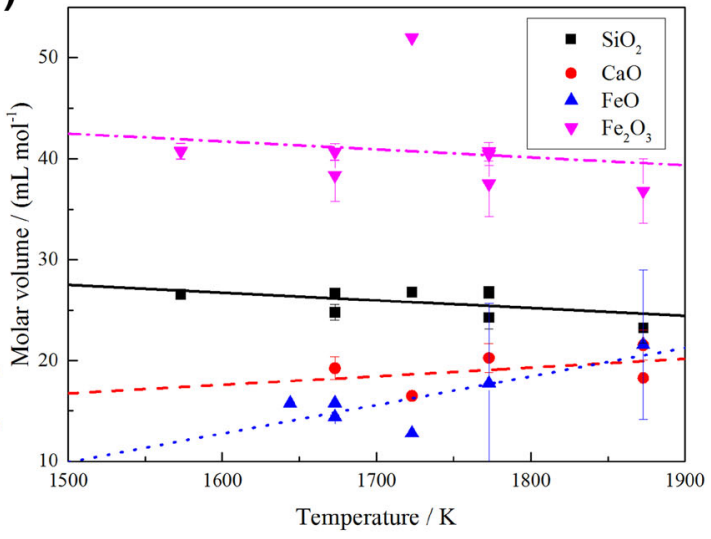

Fig. 5 Predicted molar volume of partial compounds in slag using Eqs. (12) to (15) (a) and Mills-Keene model (b). Scatters in a are experimental data from Table 4

Table 4 Molar volume of partial compounds in iron-oxides-rich molten slag

\begin{tabular}{|c|c|c|c|c|}
\hline \multirow[t]{2}{*}{ Temperature/K } & \multicolumn{4}{|c|}{ Molar volume $/\left(\mathrm{cm}^{3} \mathrm{~mol}^{-1}\right)$} \\
\hline & $\mathrm{CaO}$ & $\mathrm{Fe}_{2} \mathrm{O}_{3}$ & $\mathrm{SiO}_{2}$ & $\mathrm{FeO}$ \\
\hline 1873 & $\begin{array}{l}18.28[31] \\
21.53 \pm 1.49 \\
\quad[18]\end{array}$ & $36.38 \pm 3.21[18]$ & $23.35 \pm 1.49[18]$ & $21.58 \pm 7.40[18]$ \\
\hline 1773 & $\begin{array}{l}20.27 \pm 1.42 \\
{[18]}\end{array}$ & $\begin{array}{l}40.71 \pm 0.90,40.46 \pm 1.16 \\
\quad[17] \\
37.53 \pm 3.21[18]\end{array}$ & $\begin{array}{l}26.86 \pm 0.31,26.67 \pm 0.37 \\
\quad[17] \\
24.27 \pm 1.17[18]\end{array}$ & $17.77 \pm 7.91[18]$ \\
\hline 1723 & $16.5[24,32]$ & $52[24,32]$ & $26.8[24,32]$ & $12.8[24,32]$ \\
\hline 1673 & $\begin{array}{l}19.24 \pm 1.11 \\
{[18]}\end{array}$ & $\begin{array}{l}40.69 \pm 0.80,40.67 \pm 0.81 \\
\quad[17] \\
38.36 \pm 2.61[18]\end{array}$ & $\begin{array}{l}26.68 \pm 0.28,26.67 \pm 0.29 \\
\quad[17] \\
24.78 \pm 0.76[18]\end{array}$ & $\begin{array}{l}15.8[22] \\
14.40 \pm 0.2[18]\end{array}$ \\
\hline 1644 (melting point of $\mathrm{FeO}$ ) & & & & $13.43(\mathrm{~s}), 15.78(1)[22]$ \\
\hline 1573 & & $\begin{array}{l}40.74 \pm 0.77,40.77 \pm 0.77 \\
\quad[17]\end{array}$ & $\begin{array}{l}26.59 \pm 0.28,26.55 \pm 0.28 \\
{[17]}\end{array}$ & \\
\hline
\end{tabular}

(a)

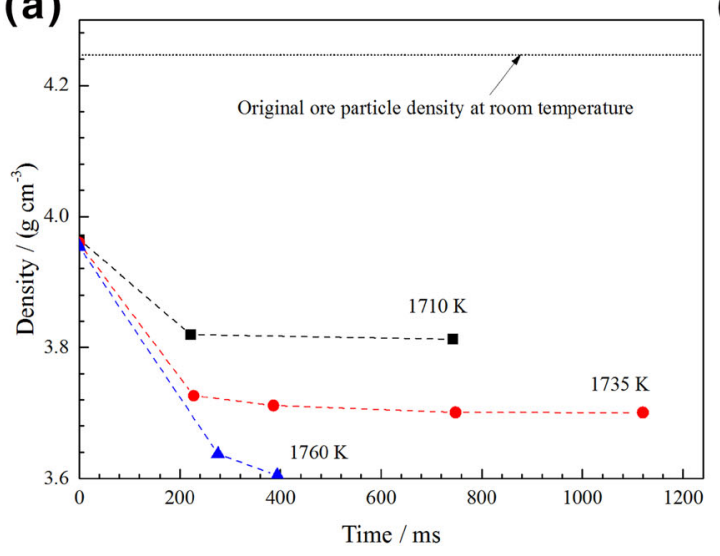

(b)

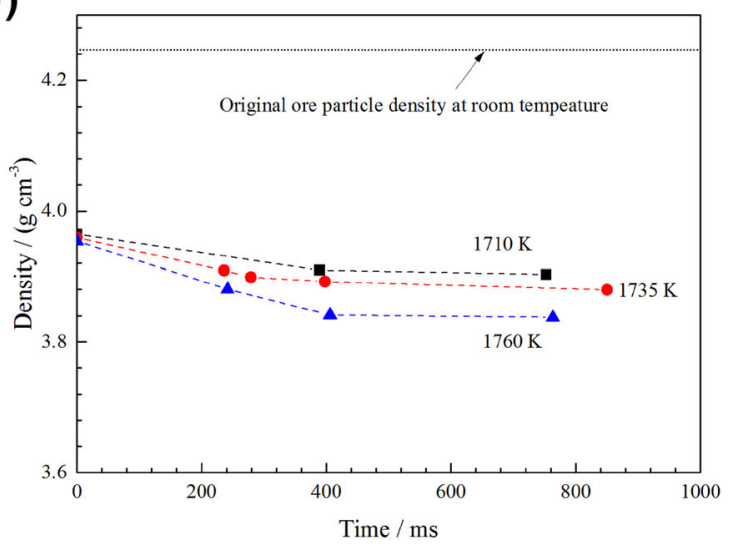

Fig. 6 Estimated densities of samples reacted in P1 gas (a) and P2 gas (b) 
Table 5 Parameters of iron oxide in reduction and melting (\%)

\begin{tabular}{|c|c|c|c|c|c|c|}
\hline \multirow[t]{2}{*}{ Parameter } & \multicolumn{3}{|c|}{ Solid phase (room temperature) } & \multicolumn{3}{|c|}{$\mathrm{FeO}$ component in slag (molten phase) } \\
\hline & Hematite & Magnetite & Wustite & $1710 \mathrm{~K}$ & $1735 \mathrm{~K}$ & $1760 \mathrm{~K}$ \\
\hline Mass & 100 & 96.66 & 90.00 & 90.00 & 90.00 & 90.00 \\
\hline Density & 100 & 98.56 & 111.14 & 86.17 & 82.48 & 79.09 \\
\hline Volume & 100 & 98.07 & 81.00 & 104.44 & 109.12 & 113.79 \\
\hline
\end{tabular}

(a)

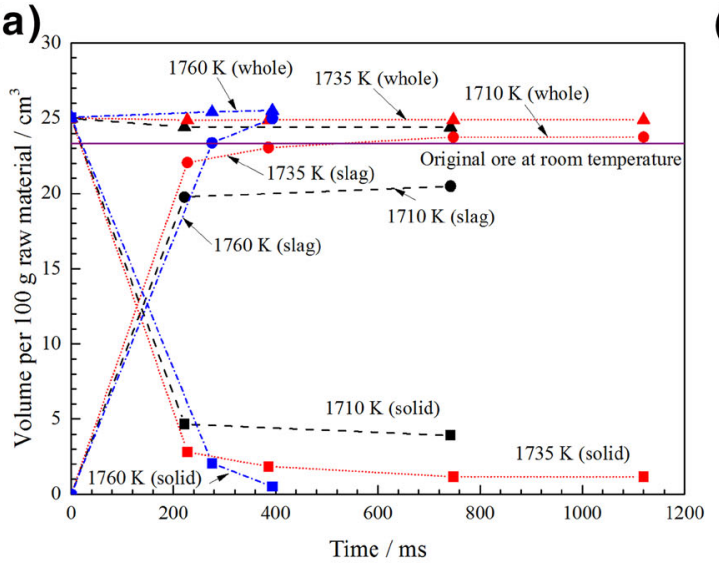

(c)

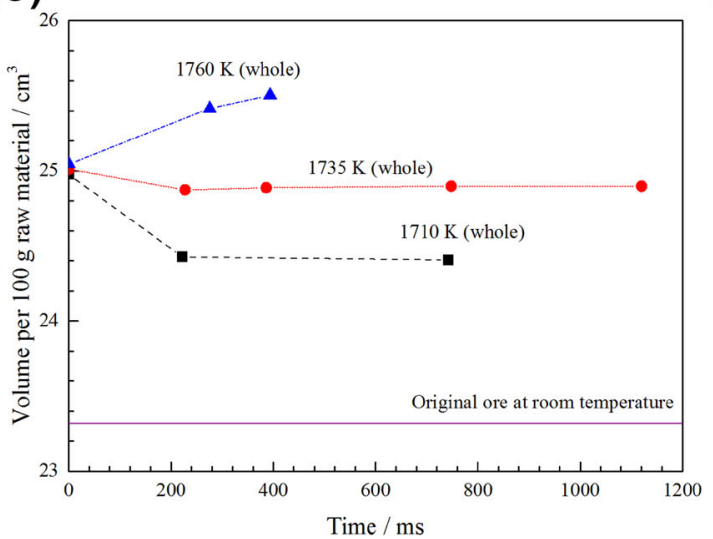

(b)

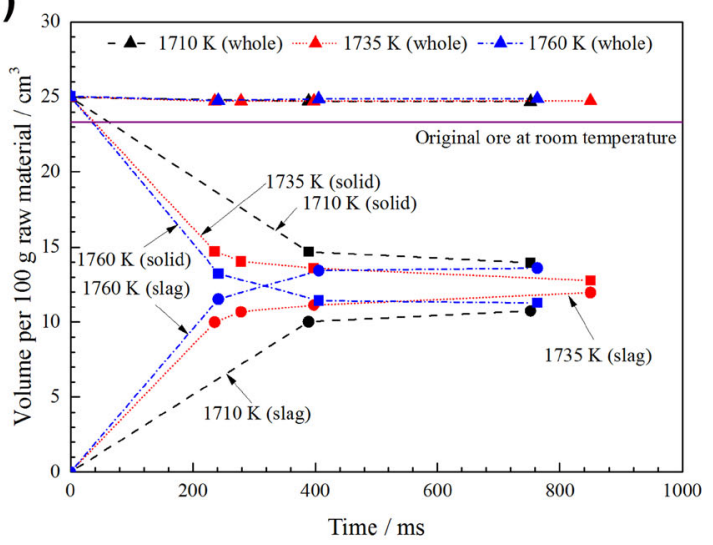

(d)

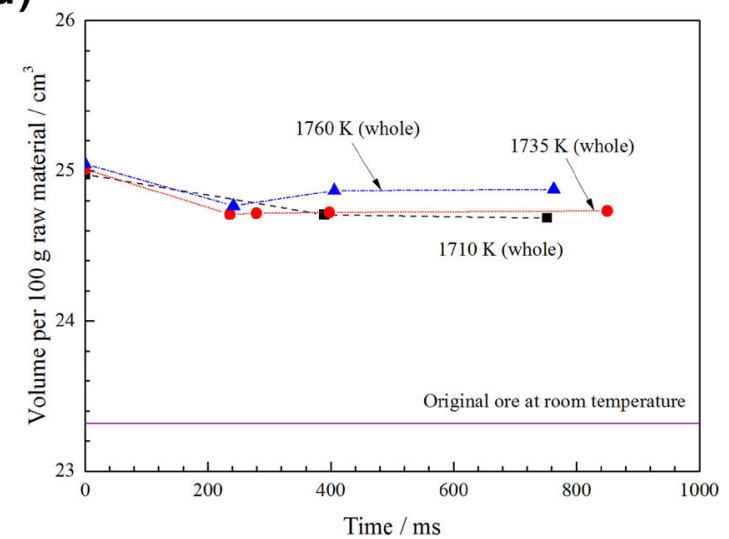

Fig. 7 Estimated volumes of $100 \mathrm{~g}$ ore particles reacted in P1 gas (a, c) and P2 gas (b, d) based on true density of particles and without considering packing manner of particles

$$
\begin{aligned}
& V_{\mathrm{FeO}}=-32.59+2.83 \times 10^{-2} T \mathrm{~cm}^{3} / \mathrm{mol} \\
& V_{\mathrm{Fe}_{2} \mathrm{O}_{3}}=54.21-7.81 \times 10^{-3} T \quad \mathrm{~cm}^{3} / \mathrm{mol}
\end{aligned}
$$

\subsection{Density and volume variations}

The initial state of the ore particles at different temperatures was assumed to be solid state. The corresponding density of the particle was calculated based on FactSage 7.0. With the assumption that the mineral amount of the non-ferrous oxides (gangue) in the ore particles does not change during the reaction, the density variation of ore particles during the reduction was estimated. According to the aforementioned analysis, ore particles reacting in P1 gas were molten particles, and the particles in $\mathrm{P} 2$ gas were solid-liquid mixtures. $\mathrm{Fe}_{3} \mathrm{O}_{4}$ is in solid phase in the calculation. Moreover, all the gangue was assumed to be already melted during the reactions. The molten slag was calculated by the modified Mills-Keene model, which was specifically used for iron-oxides-rich slag.

Figure 6 shows the estimation results of the densities of individual particles after the reaction. The density of the original ore is $4.25 \mathrm{~g} / \mathrm{cm}^{3}$ at room temperature. It can decrease to $3.96 \mathrm{~g} / \mathrm{cm}^{3}$ at $1710 \mathrm{~K}$ due to the thermal 
expansion. Moreover, significant variation of density occurs with the reduction progress. The value of density decreases more than $6.6 \%$ during the reaction in $\mathrm{P} 1$ and $\mathrm{P} 2$ gas. The reduced particles are lighter in more reducing gas and at a higher temperature. Comparing the density variation before and after the phase transformation, one could notice that the increasing slag content results in the decrease in density of reduced particles. At most, $15.1 \%$ decrease of particle density occurs at $1760 \mathrm{~K}$ in P1 gas compared with the original ore density at room temperature, which is due to the high content of slag in the reduced particles.

Due to lower density of slag than that of solid phases, the volume contribution of slag is higher than the value of the slag mass ratio. The main composition of the slag is $\mathrm{FeO}$. The reduction from hematite to solid magnetite can result in $1.93 \%$ volume swelling of the particle at room temperature. Meanwhile, the reduction from hematite to liquid wustite can result in $4.44 \%, 9.12 \%$ and $13.79 \%$ swelling at 1710,1735 and $1760 \mathrm{~K}$, respectively. As an illustration, the mass, density and volume changes of hematite after reduction and melting are provided in Table 5. To be precise, the volume and density change of $\mathrm{FeO}$ in slag includes the effect of temperature.

Figure 7 shows that only $0.48 \%$ decrease to $1.96 \%$ increase of volume variation is attributed to the decreased total mass and the density in the isothermal reduction and melting process. Thermal expansion contributes the most to the increase in volume, which is about $7.11-7.40 \%$. At most, swelling of $9.37 \%$ was observed in the reduction of ore in P1 gas at $1760 \mathrm{~K}$. Higher ratio of slag phase in the reduced particle could result in more swelling of the ore particles. Therefore, high temperature and reducing atmosphere promote swelling of the particles. Nevertheless, compared with the obvious change of density value, the total volume of the sample changes slightly during the reaction.

\subsection{Effect on velocity}

Here, the particle falling in a drop-tube furnace was studied as an illustration of findings of this study. As the researchers [5-7] indicated, three forces act on a single particle in-flight, which include the drag force $F_{\mathrm{D}}$, gravity $F_{\mathrm{G}}$ and buoyant force $F_{\mathrm{B}}$ :

$\frac{1}{6} \pi d_{\mathrm{p}}^{3} \rho_{\mathrm{p}} \frac{\mathrm{d} u_{\mathrm{p}}}{\mathrm{d} t}=F_{\mathrm{D}}+F_{\mathrm{G}}-F_{\mathrm{B}}$

where $d_{\mathrm{p}}$ is the particle diameter; $\rho_{\mathrm{p}}$ is the particle density; $t$ is the falling time of the particle; and $u_{\mathrm{p}}$ is the falling velocity of particle in the reactor. A schematic diagram of the

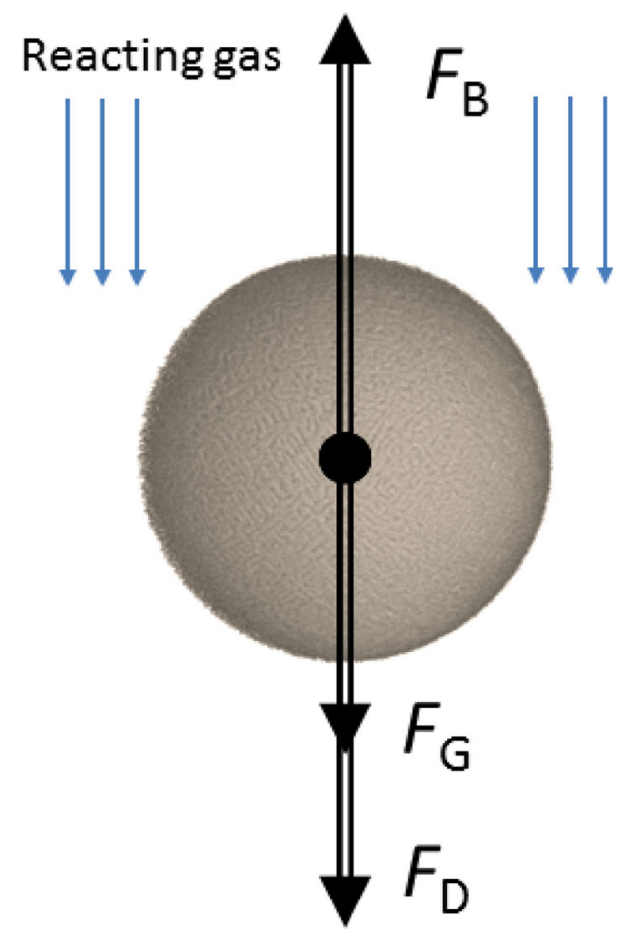

Fig. 8 Schematic diagram of forces working on a single particle in the reactor

forces working on a single particle is shown in Fig. 8 [6]. The definitions of the drag force and the difference of gravity and buoyant force are given as follows:

$F_{\mathrm{D}}=\frac{1}{2} C_{\mathrm{D}} A_{\mathrm{p}} \rho_{\mathrm{g}}\left(u_{\mathrm{g}}-u_{\mathrm{p}}\right)\left|u_{\mathrm{g}}-u_{\mathrm{p}}\right|$

$F_{\mathrm{G}}-F_{\mathrm{B}}=\frac{1}{6} \pi d_{\mathrm{p}}^{3} g\left(\rho_{\mathrm{p}}-\rho_{\mathrm{g}}\right)$

where $A_{\mathrm{p}}$ is the cross-sectional area of particle; $u_{\mathrm{g}}$ is the velocity of the reacting gas; $\rho_{\mathrm{g}}$ is the density of surrounding gas; and $C_{\mathrm{D}}$ is the drag coefficient, which is defined based on the assumption that the particle is in a Stokes flow:

$C_{\mathrm{D}}=\frac{24}{R e}=\frac{24 \mu_{\mathrm{g}}}{\rho_{\mathrm{g}} d_{\mathrm{p}}\left|u_{\mathrm{g}}-u_{\mathrm{p}}\right|}$

where $\mu_{\mathrm{g}}$ is the viscosity of gas; and $R e$ is the Reynolds number of the particle. If $u_{\mathrm{g}}$ is assumed as a constant and not be affected by the flow of particles, combining Eqs. (16) to (19), the following equation yields,

$$
\begin{aligned}
u_{\mathrm{p}}= & u_{\mathrm{g}}+\frac{d_{\mathrm{p}}^{2} g}{18 \mu_{\mathrm{g}}}\left(\rho_{\mathrm{p}}-\rho_{\mathrm{g}}\right)- \\
& {\left[\left(u_{\mathrm{g}}-u_{\mathrm{p}}^{0}\right)+\frac{d_{\mathrm{p}}^{2} g}{18 \mu_{\mathrm{g}}}\left(\rho_{\mathrm{p}}-\rho_{\mathrm{g}}\right)\right] \exp \left(-\frac{18 \mu_{\mathrm{g}} t}{d_{\mathrm{p}}^{2} \rho_{\mathrm{p}}}\right) }
\end{aligned}
$$


(a)

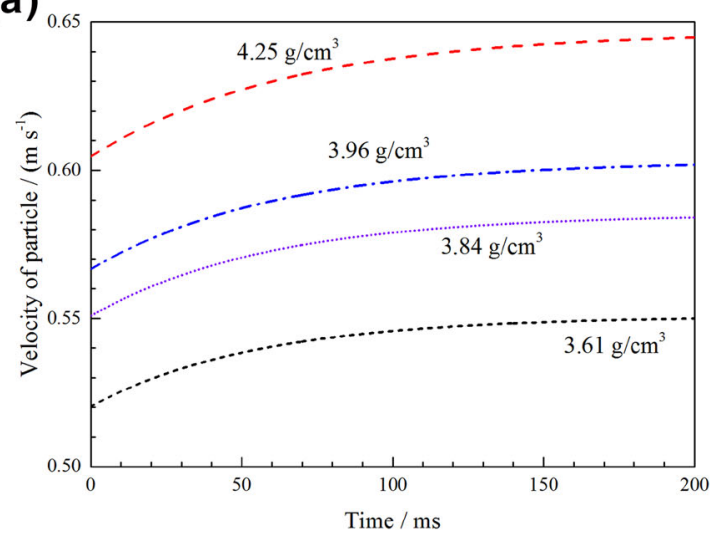

(b)

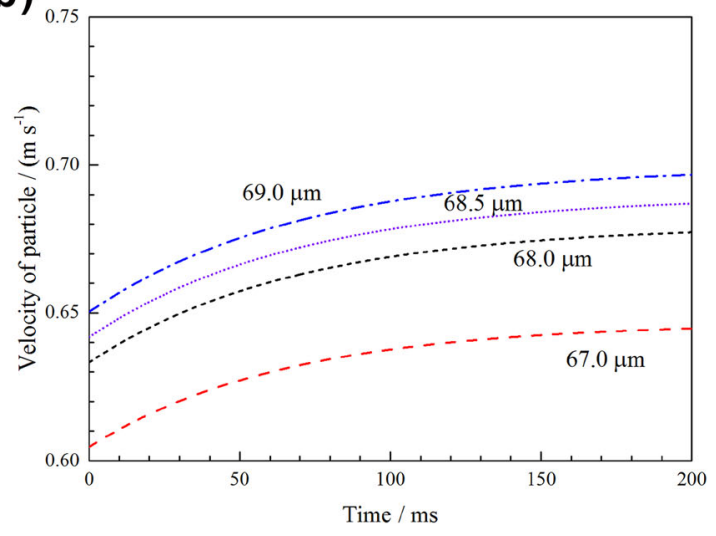

Fig. 9 Illustrations of typical falling velocity of particle in the reactor with different densities (a) and different particle sizes (b)

(a)

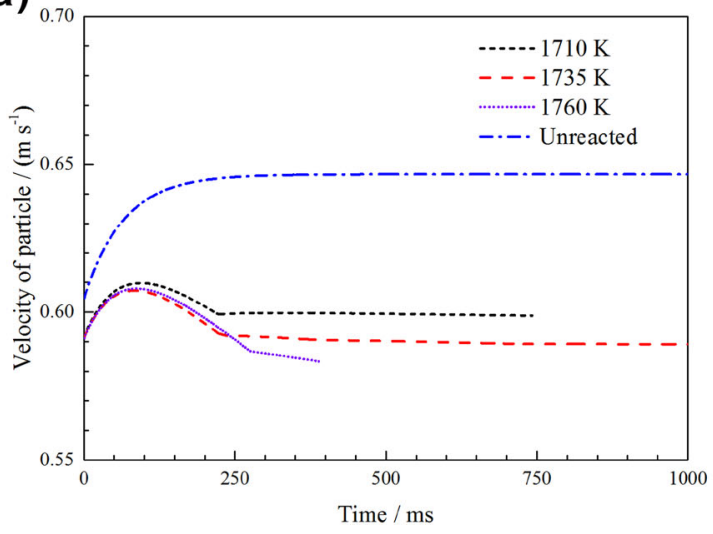

(b)

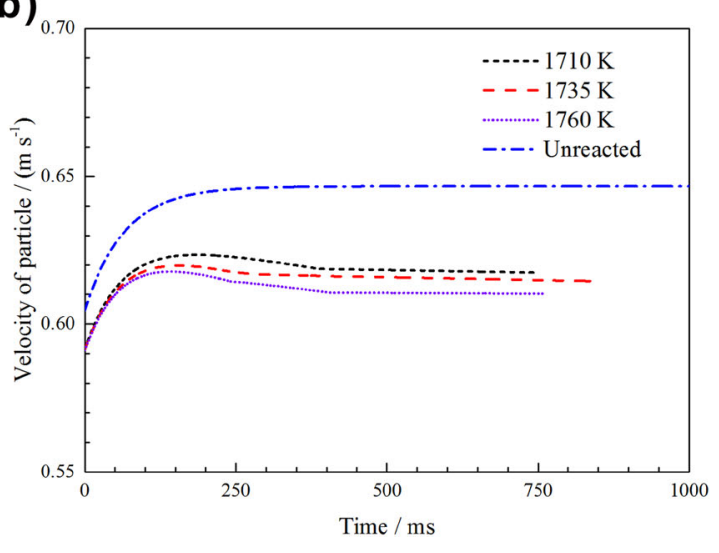

Fig. 10 Falling velocity of particles reacting in P1 gas (a) and P2 gas (b)

where $u_{\mathrm{p}}^{0}$ is the initial velocity of the particle; and $g$ is the gravitational acceleration. Equation (20) shows that the velocity of particle is affected by both the density and volume of the particle. According to the aforementioned prediction results, the volume change of the particle is insignificant compared with the density variation of the particle. The effects of particle density and size on its falling velocity are plotted in Fig. 9. The ranges of particle parameters are based on the aforementioned calculation results and the experimental conditions. It shows that the decrease in particle density can lead to the increase in its falling velocity. Decrease in the falling velocity from 6.7 to $14.7 \%$ could occur due to the density variation during the reduction process. Meanwhile, particle size change could cause the increase in the falling velocity between 5.0 and $8.1 \%$.
Based on the predicted values of density and volume of the particles reacting in $\mathrm{P} 1$ and $\mathrm{P} 2$ gases, the falling velocity of the particles was estimated, and the results are shown in Fig. 10. The change in density and volume of the particle between two points in Figs. 6 and 7 was assumed to be linear. Basically, all the falling velocities of the reacted particles are smaller than those of the unreacted particle. The velocities of the reduced particles in P2 gas are from 94.3 to $95.7 \%$ of velocity of the unreacted particle. Furthermore, due to the lower density of particles in P1 gas, the velocities of them are even smaller. The velocities of the reduced particles in P1 gas are between 90.1 and $92.6 \%$ of velocity of the unreacted particles. Moreover, higher reaction temperature results in lower falling velocity of particles in the reactor. The result implies that if the 
density and volume variations of reducing particles are ignored in the modelling of particle reaction in cyclone, the residence time of particle in-flight can be underestimated.

\section{Conclusions}

The phase transformation of the hematite ore particles during high-temperature suspension smelting was studied through high-temperature experiments. The results show that hematite can be totally reduced to a steady state within $200 \mathrm{~ms}$. $\mathrm{FeO}$ and $\mathrm{Fe}_{3} \mathrm{O}_{4}$ are the principal iron oxides in the reduced samples in 45 and 5 vol.\% CO-containing gas, respectively.

The reduced samples were assumed as a semi-molten state in the density prediction. In order to investigate the density variation of iron ore particles during the in-flight reduction process, a modified empirical model was adopted for the density prediction. The estimation results show that the melting behaviour of the ore particles at high temperature results in a decrease in the particle density in the range from 6.64 to $15.00 \%$. Furthermore, the volume change of the ore particles is mostly contributed by thermal expansion by the range from 6.63 to $9.37 \%$. Due to the combined effects of oxygen loss in reduction and volume expansion in melting, the volume of the ore particle changes slightly during the reduction. Nevertheless, the density and volume changes of the ore particles will lead to a decrease in its falling velocity in the reactor. The results imply that if the density and volume variations of reducing particles are ignored in the modelling of particle reactions in the cyclone reactor, the residence time of particle in-flight will be underestimated.

Acknowledgements This research was carried out under Project Number T41.5.13489 in the framework of the Research Program of the Materials Innovation Institute (M2i) (www.m2i.nl) supported by the Dutch government. We would like to express thanks to Mr. Koen Meijer from Tata Steel Europe (IJmuiden) for fruitful discussions in this study. Mr. Ruud Hendrikx at the Department of Materials Science and Engineering of the Delft University of Technology is acknowledged for the X-ray analysis. Dr. Michael Schick from GTT Technologies is acknowledged for the discussion on the expansivity data.

Open Access This article is distributed under the terms of the Creative Commons Attribution 4.0 International License (http://crea tivecommons.org/licenses/by/4.0/), which permits unrestricted use, distribution, and reproduction in any medium, provided you give appropriate credit to the original author(s) and the source, provide a link to the Creative Commons license, and indicate if changes were made.

\section{References}

[1] K. Meijer, M. Denys, J. Lasar, J.P. Birat, G. Still, B. Overmaat, Ironmak. Steelmak. 36 (2009) 249-251.

[2] K. Meijer, C. Zeilstra, C. Teerhuis, M. Ouwehand, J. van der Stel, Trans. Indian Inst. Met. 66 (2013) 475-481.

[3] Y. Qu, Experimental study of the melting and reduction behaviour of ore used in the HIsarna process, Delft University of Technology, Delft, The Netherlands, 2013.

[4] S. Halder, R.J. Fruehan, Metall. Mater. Trans. B 39 (2008) 796-808.

[5] D. Fan, Y. Mohassab, M. Elzohiery, H.Y. Sohn, Metall. Mater. Trans. B 47 (2016) 1669-1680.

[6] Y. Qu, Y. Yang, Z. Zou, C. Zeilstra, K. Meijer, R. Boom, ISIJ Int. 55 (2015) 952-960.

[7] S. Hayashi, Y. Iguchi, ISIJ Int. 34 (1994) 555-561.

[8] C.E. Seaton, J.S. Foster, J. Velasco, Trans. Iron Steel Inst. Jpn. 23 (1983) 497-503.

[9] T. Sharma, R. Gupta, B. Prakash, Miner. Eng. 3 (1990) 509-516.

[10] M.F. Rau, D. Rieck, J.W. Evans, Metall. Trans. B 18 (1987) 257-278.

[11] F. Tsukihashi, K. Kato, K.I. Otsuka, T. Soma, Trans. Iron Steel Inst. Jpn. 22 (1982) 688-695.

[12] S. Halder, R.J. Fruehan, Metall. Mater. Trans. B 39 (2008) 809-817.

[13] R.M. German, Sintering theory and practice, Wiley-VCH, New York, USA, 1996.

[14] E. Donskoi, D.L.S. McElwain, Ironmak. Steelmak. 28 (2001) 384-389.

[15] O.M. Fortini, R.J. Fruehan, Metall. Mater. Trans. B 36 (2005) 709-717.

[16] F.Z. Ji, D. Sichen, S. Seetharaman, Metall. Mater. Trans. B 28 (1997) 827-834.

[17] D.B. Dingwell, M. Brearley, J.E. Dickinson Jr., Geochim. Cosmochim. Acta 52 (1988) 2467-2475.

[18] D.B. Dingwell, M. Brearley, Geochim. Cosmochim. Acta 52 (1988) 2815-2825.

[19] L.J. Wang, S. Chen, K.C. Chou, Y.A. Chang, Calphad 29 (2005) $149-154$.

[20] K.C. Chou, Calphad 11 (1987) 293-300.

[21] Z. Chen, J. Liu, Z. Yu, K.C. Chou, Thermochim. Acta 543 (2012) 107-112.

[22] Y. Shiraishi, K. Ikeda, A. Tamura, T. Saito, Trans. Jpn. Inst. Metals 19 (1978) 264-274.

[23] P. Vadász, M. Havlík, V. Daněk, Open Chem. 4 (2006) 174-193.

[24] Y. Bottinga, D.F. Weill, Am. J. Sci. 269 (1970) 169-182.

[25] S. Hara, K. Irie, D.R. Gaskell, K. Ogino, Trans. Jpn. Inst. Metals 29 (1988) 977-989.

[26] Y.E. Lee, D.R. Gaskell, Metall. Trans. 5 (1974) 853-860.

[27] K. Mori, K. Suzuki, Tetsu-to-Hagane 54 (1968) 1123-1127..

[28] K.C. Mills, B.J. Keene, Int. Mater. Rev. 32 (1987) 1-120.

[29] K.C. Mills, L. Yuan, R.T. Jones, J. S. Afr. Inst. Min. Metall. 111 (2011) 649-658.

[30] S.S. Ghag, P.C. Hayes, H.G. Lee, ISIJ Int. 38 (1998) 1216-1224.

[31] T. Ličko, V. Danek, Phys. Chem. Glasses 23 (1982) 67-71.

[32] T. Ličko, V. Daněk, Z. Pánek, Chem. Pap. 39 (1985) 599-605. 